\title{
Rapid Implementation Of ERP Financials Into The Curriculum: A Success Story
}

Gary B. McCombs, (Email: gary.mccombs@emich.edu), Eastern Michigan University Mohsen Sharifi, (Email: msharifi@fullerton.edu), California State University, Fullerton

\begin{abstract}
Most academic institutions wish to provide current, up to date and real world software applications to their students and this causes a number of common difficulties. This is especially true as those applications become far larger and more complex, such as in Enterprise Resource Planning (ERP) systems, more recently referred to as Enterprise Systems. The authors' institution has a degree program in accounting information systems, and the authors believed that it was critical that ERP skills and applications be included in order to maintain the stature of the program. Although difficulties were expected, the authors nonetheless pursued various classroom ERP alternatives. This paper reports on those efforts, which culminated in the creation and offering of an ERP financial applications class in a six month time period. It is believed that such information will provide encouragement and useful information to other institutions that are considering such implementations.
\end{abstract}

\section{Introduction and Purpose}

Or ost academic institutions that wish to provide current, up to date and real world software applications to their students face a number of common difficulties. These frequently involve resource issues for hardware, software, training and ongoing administration. This is especially true as those applications become far larger and more complex, such as in Enterprise Resource Planning (ERP) systems, more recently referred to as Enterprise Systems (ES) (Davenport, 1998). These are the packages of computer applications that support many, even most, aspects of a company's (or non-profit organization's, university's or government agency's) information needs (Davenport, 2000). They are known to be information systems that help companies integrate their operations for better speed, efficiency and agility.

The authors' institution has a degree program in accounting information systems, and the authors believed that it was critical that ERP skills and applications be included in order to maintain the stature of the program. This is especially true as the ERP market is also rapidly growing in sales even to companies in the $\$ 50$ to $\$ 250$ million sales range (Piturro, 1999). Further, convergence of internationalization, E-business, E-commerce and web-enabling has caused a need for many more businesses to consider enterprise solutions (Honig 1999), and that will create a demand for knowledgeable graduates.

Although difficulties were expected, the authors nonetheless pursued different curriculum ERP alternatives. Various presentations at professional meetings were attended and several firm and professional contacts were made, most of which were discouraging in terms of necessary resource requirements. However, one of these contacts was with an alumnus working at Oracle Corporation, and as will be described later in the paper, this led to the ultimate choice and implementation of Oracle financial applications. This paper reports on those efforts, which culminated in the creation and offering of an ERP financial applications class in a six month time period. It is believed that such

Readers with comments or questions are encouraged to contact the authors via email. 
information will provide encouragement and useful information to other institutions that are considering how to incorporate ERP into their programs.

\section{Why ERP Skills?}

ERP systems are business management systems that integrate all facets of the business, including planning, manufacturing, sales, and marketing into a tightly integrated business process / information system, facilitating a seamless exchange of information across the organization (Cobb and Stoddard, 1998). They are powerful management tools to disseminate information across the enterprise by surpassing many geographical and organizational boundaries. Many organizations have benefited from these packages by reducing their process cycle time, moving the information faster among business units, and improving their financial management. The success of many ecommerce initiatives in some companies is also attributed to the early implementation of ERP. ERPs essentially promise better information and more information, with the anticipation of lower costs in an enterprise wide real time environment (Krumwiede and Jordan, 2000).

Given all of these benefits, it is imperative to integrate any desired expertise in ERP environments into the accounting curriculum. Among these skills and expertise, business process reengineering, systems design and implementation, organizational change and information technology proficiency appear to be the most important.

A few limitations that have been mentioned about ERP are the inflexibility of the system due to its highly structured nature and a long implementation cycle, although it appears that the American products are more flexible than those of European origin. All major ERP vendors are addressing the implementation time issue with various approaches to rapid setup. And the marketplace indicates that benefits far outweigh the limitations, despite reports in the press about lawsuits against software companies and consultants. Adoption of these packages by organizations is so pervasive that not integrating these packages into your curriculum is almost no longer an option.

\section{Selection of Oracle}

ERP software seriously considered included SAP R/3, J. D. Edwards and Oracle. By seriously, it is meant that direct discussions were held with the firm. We also tried to establish contact with PeopleSoft, but were not successful.

In pursuing our goal we made contact and attended one of the sessions on the SAP University Alliance Program, which was held in Chicago. Several schools were already members of the Alliance and it appeared that many other schools were considering joining the Alliance. Among the membership benefits were free software, training and limited software support (applicable to training or installation activities of the implementation). In response the members must agree to create and integrate SAP into their curriculum across departments and colleges within the university.

Although the value of such a grant by SAP amounts to roughly two million dollars, the demand on a university's internal resources was prohibitive for us. In addition to hardware and support, the university that became a member of Alliance must agree to provide staffing as well as travel funding for the faculty members who attend the training sessions or participate in the Alliance meetings. This could amount to several hundred thousand dollars. We also contacted J. D. Edwards, which had already started a limited university support program with about six universities. Although the company provided us with the necessary information for starting a system, we were not considered for their program due to a limitation on the number they were taking. Thus, we pursued Oracle Corporation.

It was through this process that information was obtained that the Oracle Academic Initiative was being expanded to include Oracle financial applications. As we pursued our inclusion in the new Oracle program, one of our alumni at Oracle, although he was not a direct part of the Academic Initiative program, became our "champion" and advisor. The key benefit that became clear was that no special computer lab would be required. All applications would be made available over the internet, which is one of the areas in which Oracle has been a leader in the marketplace. This is extremely crucial for commuter schools such as ours with a working clientele who generally 
have limited time available corresponding with the fixed times available in our campus lab locations. Further, a dedicated lab setting would likely require substantial additional hardware expenditures that are avoided by adapting to the internet environment. Students can work on various assigned tasks from any internet connected machine after a one time download of a fairly small Java applet that serves as the local machine's Oracle interface.

Our department agreed to fund a separate server for the database and financial applications. Therefore, we are using a two-tiered client server model, with the student computer representing the user presentation layer and the applications and database residing on the same server. The hardware was selected with the assistance of our champion, and this investment (about $\$ 25,000$ ) represents the only significant cost that needed to be incurred. Although we selected a Sun unit running Solaris based on working with our Oracle contact, many might find more internal support for a NT environment.

The College network administrator performed the initial hardware setup and Oracle provided the initial software installation support. Our "champion" spent an afternoon fine-tuning the software installation. When a subsequent internet connectivity difficulty arose, he provided email detail to one of the authors on how to fix the problem. He will continue to provide primarily online administration and support as he is located 300 miles from the University.

During the same week that Oracle personnel were installing the software, the authors attended an Oracle financial applications class at a regional training center. Oracle provided this class (regular price $\$ 2,400$ per attendee) at no charge; we were, however, responsible for our own travel, meals and lodging for the week. All of these activities took approximately two months (from the point of hardware order), and the authors had approximately four months (fortunately over the summer) from that point to the first scheduled class offering at their institution. Design and content of this first class offering consumed considerable time and is discussed next.

\section{Design and Content of ERP Financial Applications Class}

The authors in providing a description of their design of a first time Oracle financial applications class recognize that not all components will work as well as hoped, and expect to make ongoing modifications. The basic design involves the creation of both "academic" and "hands on" components. To accomplish this we set the following objectives for the first ERP course:

- To provide hands on experience in ERP financial systems,

- To nurture expertise among future accountants in the area of Business Process Reengineering (BPR) and its implications for ERP "back office" implementation,

- To discuss issues related to the implementation of complex ERP systems, and

- To perform research on various ERP topics.

The academic component of the class involves extensive reading and classroom reporting and discussion of those readings. It also involves lectures on a variety of related topics, such as account coding (the account code combination "flexfields" in Oracle) and the importance of database methodologies. A course pack of approximately 25 articles was assembled. In addition the book Why ERP? (Jacobs and Whybark, McGraw-Hill, 2000) was selected for use. Students are expected to provide short reports rating each on a five-point scale, summarize for each perceived strengths and weaknesses, and provide a new suggested article for inclusion in the course pack. This will partially satisfy the research objectives of the course. In the interest of continuous improvement, the student ratings of the current course pack articles are then used to determine future inclusion and new articles students have submitted are considered for future course pack inclusion. As a summary of all these materials, students prepare a report on ERP implementation implications for an organization. They also discuss the advantages and disadvantages of such systems as they relate to strategic resource commitment.

In addition, a variety of internet exercises, such as exploring various ERP and Oracle sites, are also a class component. This is combined with a team report and presentation, giving current information about one large and one smaller ERP vendor. 
The hands on component of the class involves completion of various Oracle financial applications exercises. The authors have created a series of exercises based heavily on those they encountered in their own Oracle training class. Basic Oracle features and some specifics of required exercises are demonstrated in the classroom using a notebook computer, a classroom internet connection and a projection unit attached to the notebook. Students must submit periodic printed output of various Oracle exercises as evidence of their understanding and completion.

Most students in our program commute and prefer to do any required computer work at home (or a friend's, a relative's, etc.). The required Java applet is downloaded on the first connection to our site; download and installation instructions are included (the installed size is only about $12 \mathrm{Mb}$ ) on the site. Although most students will complete the required Oracle exercises from their own PC, the authors' institution does not require the purchase of a computer as is being done in more and more universities. Therefore, arrangements were made to have the Java applet installed on selected machines in the College lab.

Oracle as delivered includes a sample company (Vision) for which students perform various tasks. Although we are currently running only one section per semester, it is possible to create multiple instances of the sample for use in multiple sections and courses. With this in mind, we sized our server to comfortably handle three sections per semester. With a little diligence one can modify Vision as delivered to accommodate preferences and needs. For example, we have allowed students to post without approval, have added more accounts and also switched the flexfield separator from a dash to a dot to facilitate easier data entry. We have then saved these changes as a base from which to start each semester.

As a support system for the class, the authors have created an online classroom forum for the sharing of ideas and information. Our institution has an online system that they call "Caucus" that allows faculty to set up a site for students to leave comments, ideas, questions and suggestions, with access available to all students in the class. Students are encouraged to maximize their use of this and to assist other students by being given grade incentives to do so. As a result we hope to create a knowledge base system for the future. This is being developed and implemented based on experiences of large organizations such as Xerox Corporation (Brown and Duguid, 2000). Xerox has created a system in which all technicians who work on document machines communicate and share their experiences with each other. As a result of this collaboration, the company has cataloged the collected information in a database that is accessible to all the technicians throughout the world. This initiative has culminated in significant cost savings and more effective service to the customers. We hope to create such a catalog that will be used by our students in the future.

One very strong recommendation is that the academic and hands on components be run concurrently. In our first offering we ran the academic, then the hands on, and when the inevitable computer "glitch" occurred we were left scrambling (for two weeks). By running both concurrently, any computer "downtime" is more easily filled with other activities.

The authors' institution is a large public university that has a typically long (several years) bureaucratic process for the creation of new courses. However, since along the lines of business process reengineering, the authors wished to create a course that would be radical rather than evolutionary in both its design and implementation (Jarvenpaa and Stoddard, 1998), the first offerings will be under an available "Special Topics" course number while normal new course processing is undertaken.

\section{Conclusion}

Although significant effort has been involved in developing an ERP financial applications class using Oracle, very little cost has been incurred other than purchase of a server. The course was relatively easy to start and implement given that neither of the authors is an expert at server or database installation, but does require continuous time and learning involvement by one or more interested faculty. Specifically, keys to success include having the right internal owner and the right internal support (Laughlin 1999). The announced "in kind" value of the software and services received has provided excellent public relations for the department both inside and outside the university. It is hoped that this paper on rapidly implementing an ERP financial applications class will provide ideas, guidance and incentives for other academic institutions to do so as well. 
We also hope that this experience will help us with faster integration of other Oracle modules into our curriculum, such as including some basic work in our introductory AIS class. We also have started interacting with other departments within our college and hope to create a much bigger ERP teaching environment for our students, for example, with the use of Human Resource and Supply Chain modules.

\section{Suggestions for Future Research}

This paper reports on a single classroom experience with a single ERP software product. Since it is unlikely that any institution could afford to support multiple ERP products in a classroom environment, it would be interesting and useful to have similar reports of similar implementations for other ERP products.

\section{References}

1. Brown, J.S. and Paul Duguid, "Balancing Act: How to Capture Knowledge without Killing It," Harvard Business Review, May-June 2000, pp. 73-80.

2. Cobb, Charles G. and Donna B. Stoddard, "Enterprise Resource Planning (ERP) Systems," Center for Information Management Studies, Babson College, Working Paper Series \#98-06, July 1998, pp. 1-24.

3. Davenport, Thomas H., "Putting the Enterprise into the Enterprise System," Harvard Business Review, July-August 1998, pp. 121-131.

4. Davenport, Thomas H., Mission Critical: Realizing the Promise of Enterprise Systems, Harvard Business School Press, Boston, 2000.

5. Honig, Susan A., "The Changing Landscape of Computerized Accounting Systems, " The CPA Journal, May 1999, pp. 14-16.

6. Jarvenpaa, Sirkka L. and Donna B. Stoddard, "Business Process Redesign: Radical and Evolutionary Change," Journal of Business Research, 1998:41, pp. 15-27.

7. Krumwiede, Kip R. and Win G. Jordon, "Reaping the Promise of Enterprise Resource Systems," Strategic Finance, October 2000, pp. 49-52.

8. $\quad$ Laughlin, Stephen P., “An ERP Game Plan,” Journal of Business Strategy, January/February 1999, pp. $32-$ 37.

9. Piturro, Marlene, "How Midsize Companies Are Buying ERP,” Journal of Accountancy, September 1999, pp. 41-48. 
Notes 